NASA/TM-2004-213307

\title{
Microsystem Cooler Development
}

\author{
Matthew E. Moran \\ Glenn Research Center, Cleveland, Ohio \\ Danielle M. Wesolek, Bruk T. Berhane, and Keith J. Rebello \\ Johns Hopkins University, Laurel, Maryland
}


Since its founding, NASA has been dedicated to the advancement of aeronautics and space science. The NASA Scientific and Technical Information (STI) Program Office plays a key part in helping NASA maintain this important role.

The NASA STI Program Office is operated by Langley Research Center, the Lead Center for NASA's scientific and technical information. The NASA STI Program Office provides access to the NASA STI Database, the largest collection of aeronautical and space science STI in the world. The Program Office is also NASA's institutional mechanism for disseminating the results of its research and development activities. These results are published by NASA in the NASA STI Report Series, which includes the following report types:

- TECHNICAL PUBLICATION. Reports of completed research or a major significant phase of research that present the results of NASA programs and include extensive data or theoretical analysis. Includes compilations of significant scientific and technical data and information deemed to be of continuing reference value. NASA's counterpart of peerreviewed formal professional papers but has less stringent limitations on manuscript length and extent of graphic presentations.

- TECHNICAL MEMORANDUM. Scientific and technical findings that are preliminary or of specialized interest, e.g., quick release reports, working papers, and bibliographies that contain minimal annotation. Does not contain extensive analysis.

- CONTRACTOR REPORT. Scientific and technical findings by NASA-sponsored contractors and grantees.
- CONFERENCE PUBLICATION. Collected papers from scientific and technical conferences, symposia, seminars, or other meetings sponsored or cosponsored by NASA.

- SPECIAL PUBLICATION. Scientific, technical, or historical information from NASA programs, projects, and missions, often concerned with subjects having substantial public interest.

- TECHNICAL TRANSLATION. Englishlanguage translations of foreign scientific and technical material pertinent to NASA's mission.

Specialized services that complement the STI Program Office's diverse offerings include creating custom thesauri, building customized databases, organizing and publishing research results ... even providing videos.

For more information about the NASA STI Program Office, see the following:

- Access the NASA STI Program Home Page at http://www.sti.nasa.gov

- E-mail your question via the Internet to help@sti.nasa.gov

- Fax your question to the NASA Access Help Desk at 301-621-0134

- Telephone the NASA Access Help Desk at 301-621-0390

- Write to:

NASA Access Help Desk

NASA Center for AeroSpace Information 7121 Standard Drive

Hanover, MD 21076 
NASA/TM-2004-213307

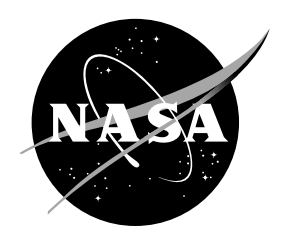

\section{Microsystem Cooler Development}

Matthew E. Moran

Glenn Research Center, Cleveland, Ohio

Danielle M. Wesolek, Bruk T. Berhane, and Keith J. Rebello

Johns Hopkins University, Laurel, Maryland

Prepared for the

Second International Energy Conversion Engineering Conference sponsored by the American Institute of Aeronautics and Astronautics Providence, Rhode Island, August 16-19, 2004

National Aeronautics and

Space Administration

Glenn Research Center 


\section{Acknowledgments}

The authors would like to thankfully acknowledge the technical contributions from John L. Champion, Ann M. Darrin, and Robert Osiander; the design expertise of Rafal P. Szczepanowski and Glenn A. Chase; as well as Frederick P. Gick, Richard L. Edwards, and John S. Lehtonen in fabrication and assembly.

This report contains preliminary

findings, subject to revision as analysis proceeds.

Available from

NASA Center for Aerospace Information 7121 Standard Drive

Hanover, MD 21076
National Technical Information Service 5285 Port Royal Road Springfield, VA 22100 


\title{
Microsystem Cooler Development
}

\author{
Matthew E. Moran \\ National Aeronautics and Space Administration \\ Glenn Research Center \\ Cleveland, Ohio 44135 \\ Danielle M. Wesolek, Bruk T. Berhane, and Keith J. Rebello \\ Johns Hopkins University \\ Applied Physics Laboratory \\ Laurel, Maryland 20723
}

\begin{abstract}
A patented microsystem Stirling cooler is under development with potential application to electronics, sensors, optical and radio frequency (RF) systems, microarrays, and other microsystems. The microsystem Stirling cooler is most suited to volume-limited applications that require cooling below the ambient or sink temperature. Primary components of the planar device include: two diaphragm actuators that replace the pistons found in traditional-scale Stirling machines; and a micro-regenerator that stores and releases thermal energy to the working gas during the Stirling cycle. The use of diaphragms eliminates frictional losses and bypass leakage concerns associated with pistons, while permitting reversal of the hot and cold sides of the device during operation to allow precise temperature control. Three candidate micro-regenerators were custom fabricated for initial evaluation: two constructed of porous ceramic, and one made of multiple layers of nickel and photoresist in an offset grating pattern. An additional regenerator was prepared with a random stainless steel fiber matrix commonly used in existing Stirling machines for comparison to the custom fabricated regenerators. The candidate regenerators were tested in a piezoelectric-actuated test apparatus designed to simulate the Stirling refrigeration cycle. In parallel with the regenerator testing, electrostatically-driven comb-drive diaphragm actuators for the prototype device have been designed for deep reactive ion etching (DRIE) fabrication.
\end{abstract}

\section{Introduction}

$\mathrm{M}$ INIATURIZATION of thermal management methods to accommodate distributed and microelectronic heat sources is receiving increased attention. Micro-scale thermal management offers several enticing opportunities: ${ }^{1}$

1. Ability to "spot cool" high heat flux regions with unparalleled resolution to bring down critical junction temperatures.

2. Potential for macro-level performance leaps by optimizing micro-level heat transfer.

3. Improved integration of thermal management at the chip level using compatible semiconductor materials and fabrication techniques.

4. Enabling of system-level miniaturization to support the pervasive trend toward increased capabilities in smaller devices.

Micro-refrigerators and coolers have a unique characteristic for electronics cooling that differentiates them from all other thermal management technologies: the ability to generate cooling temperatures below ambient or ultimate sink temperature. Thermoelectric or Peltier coolers are the most common refrigeration devices used for chip and board level electronics cooling, and have been scaled to the micro-domain. Unfortunately thermoelectrics have low efficiencies resulting in high power requirements and added waste heat.

Meso and/or micro scale devices operating on the Stirling cycle are an attractive potential alternative based on the high efficiencies realized for Stirling machines. A further attraction of micro-scale Stirling devices is the ability of the Stirling cycle to be used for generating power where a temperature difference is maintained; or, in the "reverse" refrigeration cycle with power input. However, attempts to miniaturize such a device for application in electronics cooling have been scale-limited by the use of traditional components (e.g., pistons, linkages, and pressure vessels) and traditional fabrication methods. ${ }^{2,3}$ As a result, Stirling coolers have been impractical for most 
electronic packaging applications. The only attempt known by the authors to approach the micro-scale is documented in a series of cryocooler patents that use diaphragms instead of pistons to drive the working gas. ${ }^{4}$

The initial objective of the effort described in this paper is to develop a micro-scale Stirling cooler with a $30 \%$ of Carnot efficiency and a no-load temperature lift of $20^{\circ} \mathrm{C}$. The prototype unit is expected to have a footprint on the order of one square centimeter, with a thickness limited to several millimeters in order to accommodate integration of the device with electronic packages.

\section{A. Concept}

Stirling machines face two significant dilemmas at meso and/or micro scale: piston frictional losses and axial thermal conduction losses. Frictional losses scale unfavorably relative to performance in the micro domain. As surface forces, frictional losses diminish only as the square of unit length; whereas, performance diminishes roughly as volume or the cube of unit length. Put another way, a Stirling device that has been reduced in overall size by a factor of one-thousand will have a vastly reduced performance by a factor of one-billion (as measured by output power or refrigeration capacity), while frictional losses will only be reduced by a factor of one-million.

The regenerator of a Stirling device maintains the temperature differential between the hot temperature source and cold temperature sink, while simultaneously storing and releasing heat from/to the working gas on every cycle. Axial thermal conduction through the regenerator introduces a direct loss from the device performance. At traditional scales, this loss mechanism is manageable. However, as the conduction length is reduced to the order of millimeters or less, minimizing axial conduction losses becomes paramount.

A patented microsystem Stirling cooler concept ${ }^{5}$ that addresses the key issues of frictional and axial thermal conduction losses is sketched in Fig. 1. Figure 2 provides a more detailed view of a portion of the device in crosssection.

Referring to Fig. 2, frictional losses are eliminated by replacing conventional pistons and associated linkages with

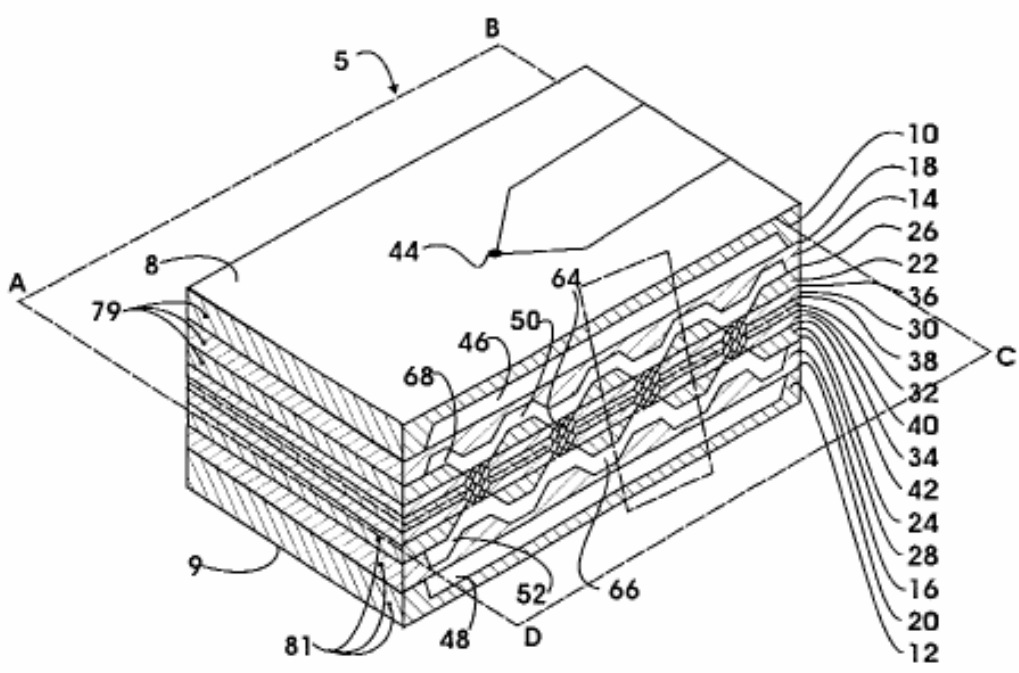

Figure 1.-Microsystem Stirling cooler (US Patent 6,385,973 B1).

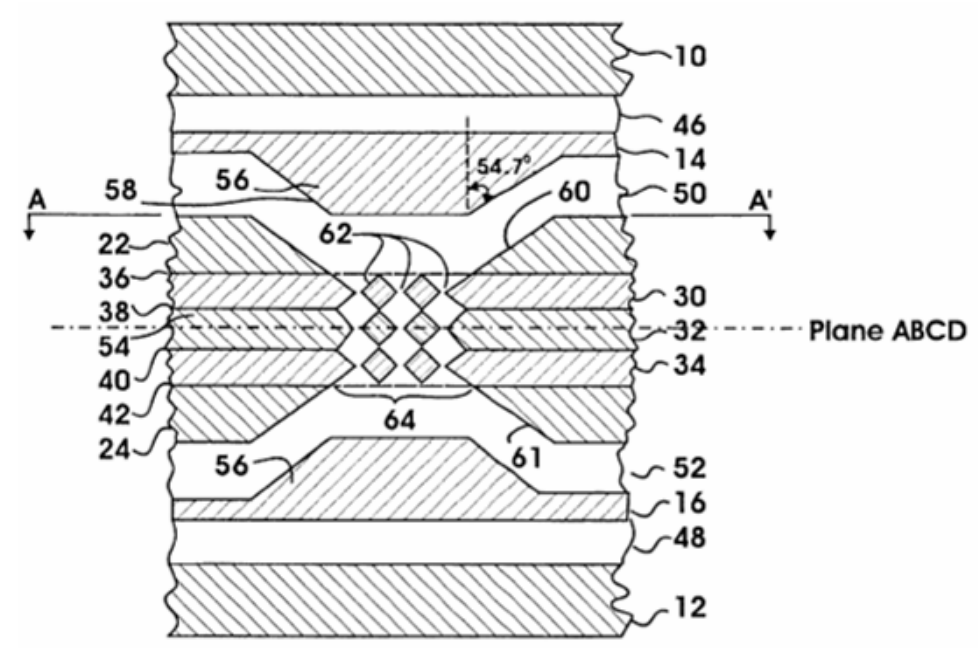

Figure 2.-Cross-section view of portion of cooler concept. electrostatically-driven solid silicon diaphragms (labels $14 \& 16$ ). The device is fabricated with semiconductor processing techniques to produce a device with planar geometry. The result is a flat cold surface for extracting heat and an opposing flat hot surface for thermal dissipation (labels $10 \& 12$ ). A thin film temperature sensor deposited on one of the surfaces provides control feedback. This sensor, along with the ability to switch hot and cold ends by altering the cycle with control software, permits the device to be used for precise thermal control as well as for active cooling. 
The expansion and compression diaphragms are the only moving parts (labels $14 \& 16$ ), and are deflected toward and away from the regenerator region (labels $22 \& 24$ ) in phase-shifted sinusoidal fashion to produce the Stirling refrigeration cycle. Expansion of the working gas in the space directly adjacent to the expansion diaphragm in each cycle creates a cold end for extracting heat; while compression at the other end creates a hot region for dissipating heat (labels $50 \& 52$ ).

Heat is transferred to and from the working gas as it is forced through the regenerator region (label 62) by the moving diaphragms. The slanted geometries of the diaphragm and regenerator surfaces are characteristic of the wet etching process used to create the structure, and advantageously increase the potential swept volume in the expansion and compression regions. The regenerator can alternatively be made up of constant cross-section passages that are created after the regenerator layers are bonded.

Issues associated with the breakdown of continuum behavior in the working gas have been examined, ${ }^{6}$ and the initial design was intentionally sized to be above the continuum scale limits. Future components may be selectively scaled to take advantage of noncontinuum behavior (e.g., higher voltage breakdown in the electrostatic-driven diaphragms).

\section{B. Evolved Design}

Evolution of the design has resulted in the minimization of inactive areas in the regenerator and the use of electrostatic comb drives to improve diaphragm deflection and force generation. Figure 3 illustrates the current prototype design consisting of a regenerator sandwiched between compression and expansion chambers.

Each of the chambers is formed by an electrostatic vertical comb drive actuator constructed from two silicon pieces which are aligned and epoxy bonded together. The top component consists of a $1.1 \mathrm{~cm}$ diameter section of radial comb fingers attached to a $2.2 \mathrm{~cm}$ frame by a set spiral silicon springs. A 3 micron layer of $\mathrm{CP}-1$ polyimide ${ }^{*}$ is bonded to the top piece to form an airtight sealed diaphragm. The bottom component of the pumping chamber has a $1.1 \mathrm{~cm}$ diameter section of radial comb fingers with thru slots to allow the working gas to pass through the underlying regenerator.

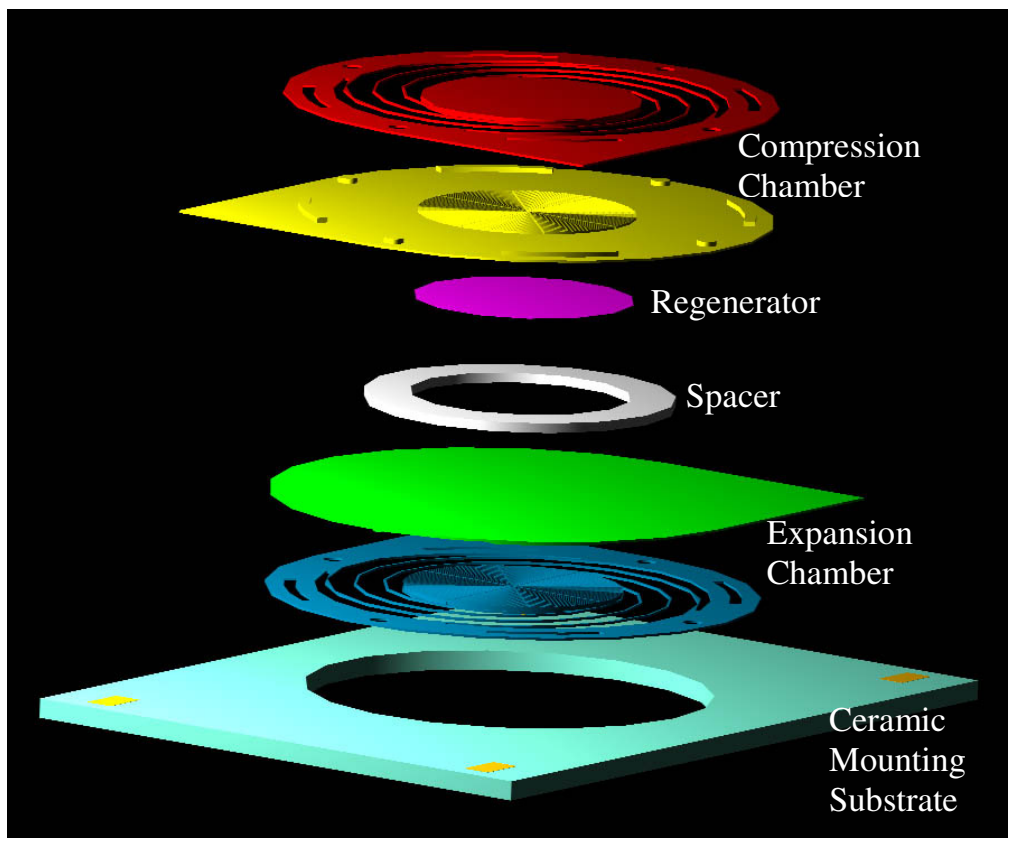

Figure 3. Evolved prototype microsystem cooler design.

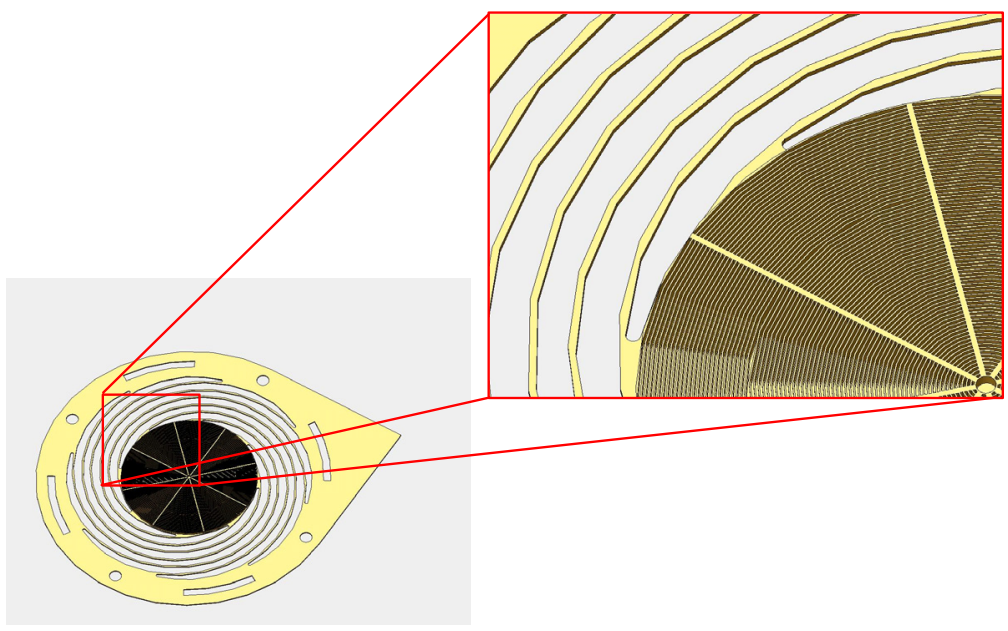

Figure 4. Electrostatic comb-drive actuator diaphragm design.

\footnotetext{
"Available from SRS Technologies, Huntsville AL.
} 
As shown in Fig. 4, the comb drives consist of concentric fingers 25 microns in width with gaps of 45 microns between fingers such that when the fingers are interlocked there is a distance of 10 microns between them. The fingers and thru slots are fabricated by using a Deep Reactive Ion Etching (DRIE) process to remove silicon from both the front and backside of the wafer. Afterwards an oxide coating electrically isolates the top and bottom pieces from each other.

Traditional comb drive actuators are made in a surface micromachining process. Use of the DRIE process, with its capability for vertical high aspect ratios, enables a significantly greater number of fingers. The increased number of fingers allows the generation of higher actuation forces and, in turn, larger displacements. Analytical calculations indicate that a $60 \mathrm{~V}$ potential across the comb drive actuator generates $2.3 \mathrm{mN}$ of force which displaces the CP-1 diaphragm 151 microns.

\section{Test Apparatus}

Feasibility of the microsystem Stirling cooler depends heavily on the design and performance of the regenerator. The regenerator design must minimize axial conduction and pressure drop, while maximizing heat transfer to and from the working gas during operation. A specially designed test fixture was constructed to characterize the candidate regenerator designs under operational conditions of interest, and to demonstrate the feasibility of producing a Stirling refrigeration cycle at the small scale and high frequencies desired.

\section{A. Test Fixture}

Figure 5 shows an assembled view (top) and exploded view (bottom) of the micro-regenerator test fixture. A photograph of the various components is shown in Fig. 6.

The regenerator to be tested is placed in the center of the fixture assembly between two "pistons" that are displaced by piezoelectric actuators using a plumbum (lead) zirconate titanate (PZT) coating. The pistons, in turn, drive a pair of membranes (shown as copper in Fig. 5) that are in direct contact with the working gas.

Appropriate working gas volume exists on either side of the regenerator to accommodate the expansion and compression required of the Stirling cycle. The PZT actuators are electronically controlled to drive the Stirling refrigeration cycle within the fixture.

Initial tests indicated that the actuators were generating and transferring significant heat in the original configuration to the regenerator portion of the fixture. Therefore, modifications were made to the test fixture to thermally isolate the piezoelectric actuators from the device inner components. Figure 7 is a photograph of the modified fixture showing the low thermal conductivity stand-offs separating the actuators from the remaining components.

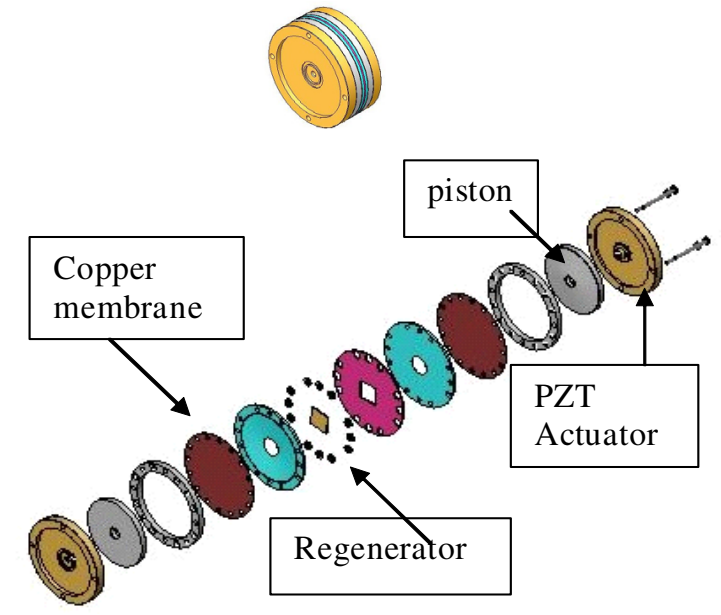

Figure 5.-Micro-regenerator test fixture design.

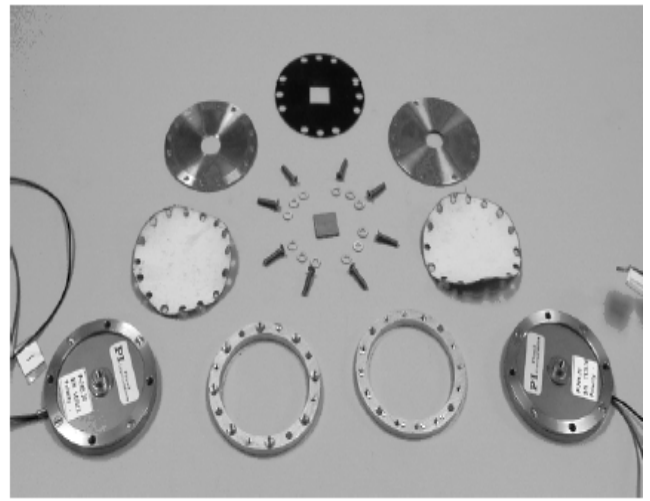

Figure 6.-Test fixture components.

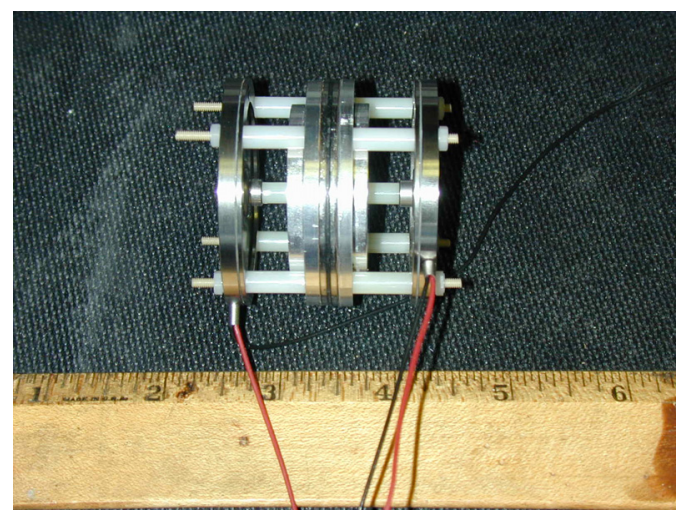

Figure 7.-Modified test fixture. 


\section{B. Regenerators}

Four candidate regenerators were prepared for testing in the test fixture with maximum dimensions of one centimeter square by one millimeter thick:

- Ten layer composite nickel-photoresist offset grating regenerator fabricated using LIGA $^{\dagger}$ techniques

- Large-grain porous ceramic regenerator

- Small-grain porous ceramic regenerator

- Random stainless steel fiber regenerator

The nickel-photoresist grating regenerator (see Fig. 8), was designed to minimize layer-to-layer axial conduction and pressure drop while providing sufficient nickel material for regenerative heat transfer to and from the working gas. Each grating layer is composed of 50 microns of nickel deposited on 40 microns of low conductivity photoresist. The openings in the gratings are 100 microns square and the solid walls are approximately 20 microns thick, resulting in a porosity of approximately $60 \%$. Each grating layer is offset by 50 microns in both directions, so that alternating layers are duplicates and in precise alignment. The resulting offset serves two key purposes: 1) disruption of the boundary layer for improved heat transfer between the working gas and regenerator; and 2) minimization of the contact area between layers. The combination of low contact area between layers, and the use of low conductivity photoresist at the interface, results in low axial conduction losses.

Two variations of porous ceramic regenerators - one with $184 \mu \mathrm{m}$ grains and the other with $416 \mu \mathrm{m}$ grains were also prepared for testing. Figure 9 shows the ceramic regenerators in the test fixture mounting with a separate magnified photograph illustrating the structure of the grains. Porous ceramic regenerators were selected based on the large void volume and low thermal conductivity that translate into low axial conduction losses and pressure drop.

Finally, a regenerator composed of randomly oriented 13-micron thick stainless steel fiber was prepared for testing. Figure 10 shows a photograph of the material along with a magnified view of the fibers. This material is used in state-of-the-art Stirling machines currently assembled at traditional scales, and provides the advantage of high porosity (i.e., roughly $90 \%$ ) and low axial thermal conduction for an all-metal matrix.

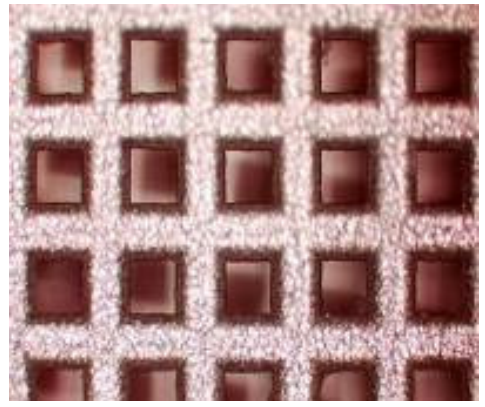

Figure 8.-Nickel-photoresist regenerator.
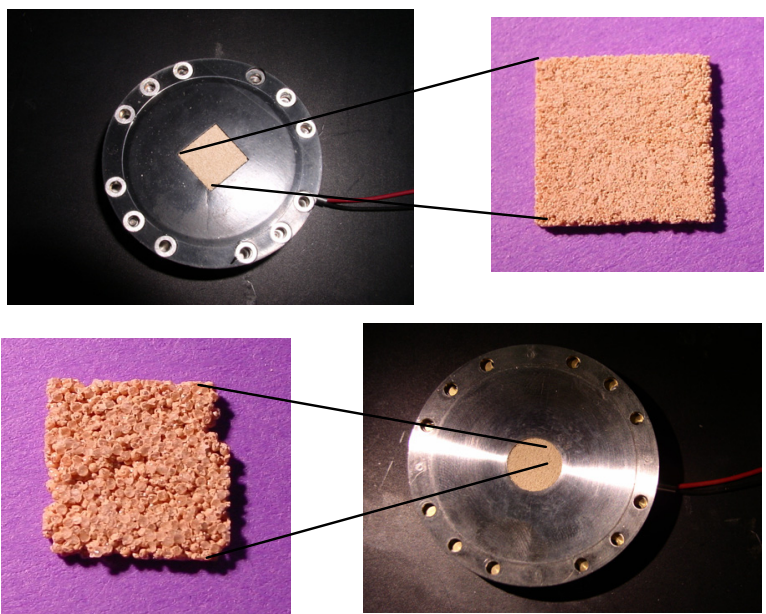

Figure 9.-Porous ceramic regenerators.

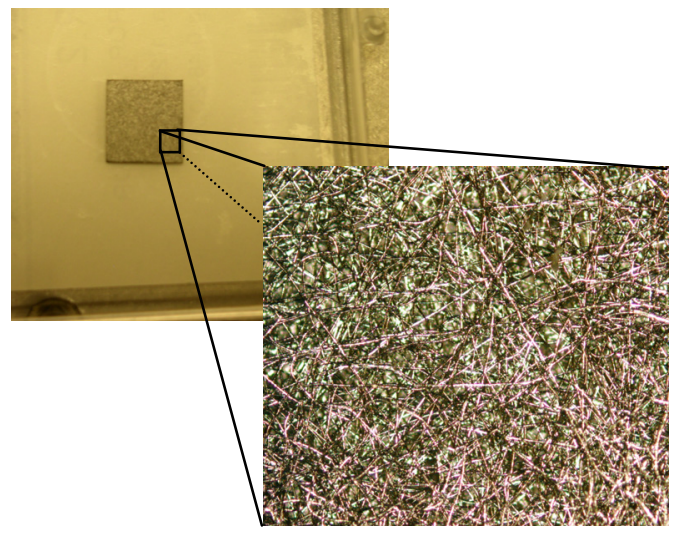

Figure 10.-Random stainless steel fiber regenerator.

\footnotetext{
"LIGA is a German acronym ("LIthographie, Galvanoformung, und Abformung) for a set of micromachining methods comprised of lithography, electroplating, and molding. This regenerator was custom fabricated and assembled by Polar Thermal Technologies, Oak Creek, WI.

\# Information on the use of this material in traditional size Stirling machines, and a sample of the material for testing, was provided by David Gedeon of Gedeon Associates. The material is manufactured by Bekaert (Belgium).
} 


\section{Actuated Piston Displacement Calibration}

A microwave interferometer, shown in Fig. 11, was used to measure the displacement of the piezoelectric actuated piston on the regenerator test fixture. Initial testing provided verification of the wavelength of the generated microwaves, and calibration information that was used to obtain displacement data.

During the calibration measurement, the regenerator test fixture was stabilized at incremental distances from the microwave cone source. In this case, the modulator regulator externally modulated the amplitude of the microwaves. Half of the modulated microwave energy was directionally coupled to a balanced mixer, and half was passed to the reflective surface of the piston. The returning signal was directionally coupled such that the local oscillator and radio frequency signals recombined at the balanced mixer where the resultant direct current response was measured. A typical linear calibration curve is shown in Fig. 12.

\section{Test Results}

\section{A. Diaphragm Membrane Displacement}

With each of the regenerators fixed inside the test fixture, membrane displacement measurements were obtained with the microwave interferometer previously discussed. Initial calibration measurements provided the maximum sensitivity point-away-from-source position in which to conduct the membrane displacement tests. The motion of the passive membrane was measured as the active membrane was driven at various frequencies via

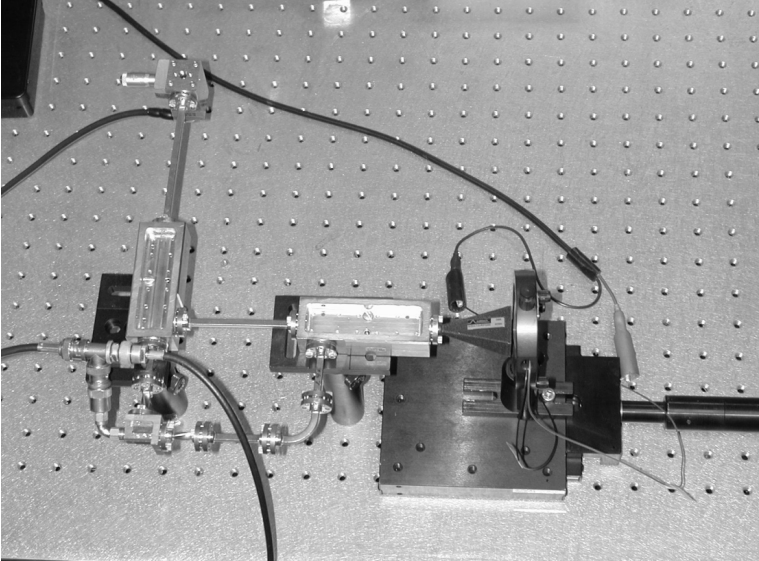

Figure 11.-Microwave interferometer.

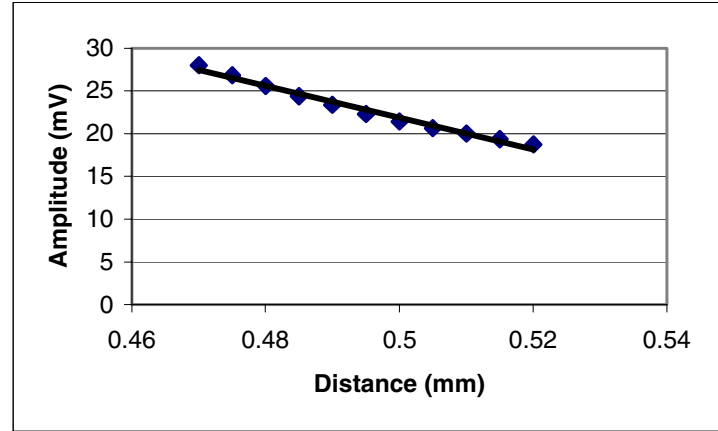

Figure 12.-Displacement calibration curve. piezoelectric actuation. The displacement as a function of applied input voltage is shown in Figs. 13 and 14 for each regenerator. The maximum displacement for each regenerator at system resonance and $1000 \mathrm{~Hz}$ are summarized in Table I for $400 \mathrm{~V}$ input to the piezoelectric actuator. System resonance was found experimentally by frequency sweeping to determine the maximum membrane deflection. 

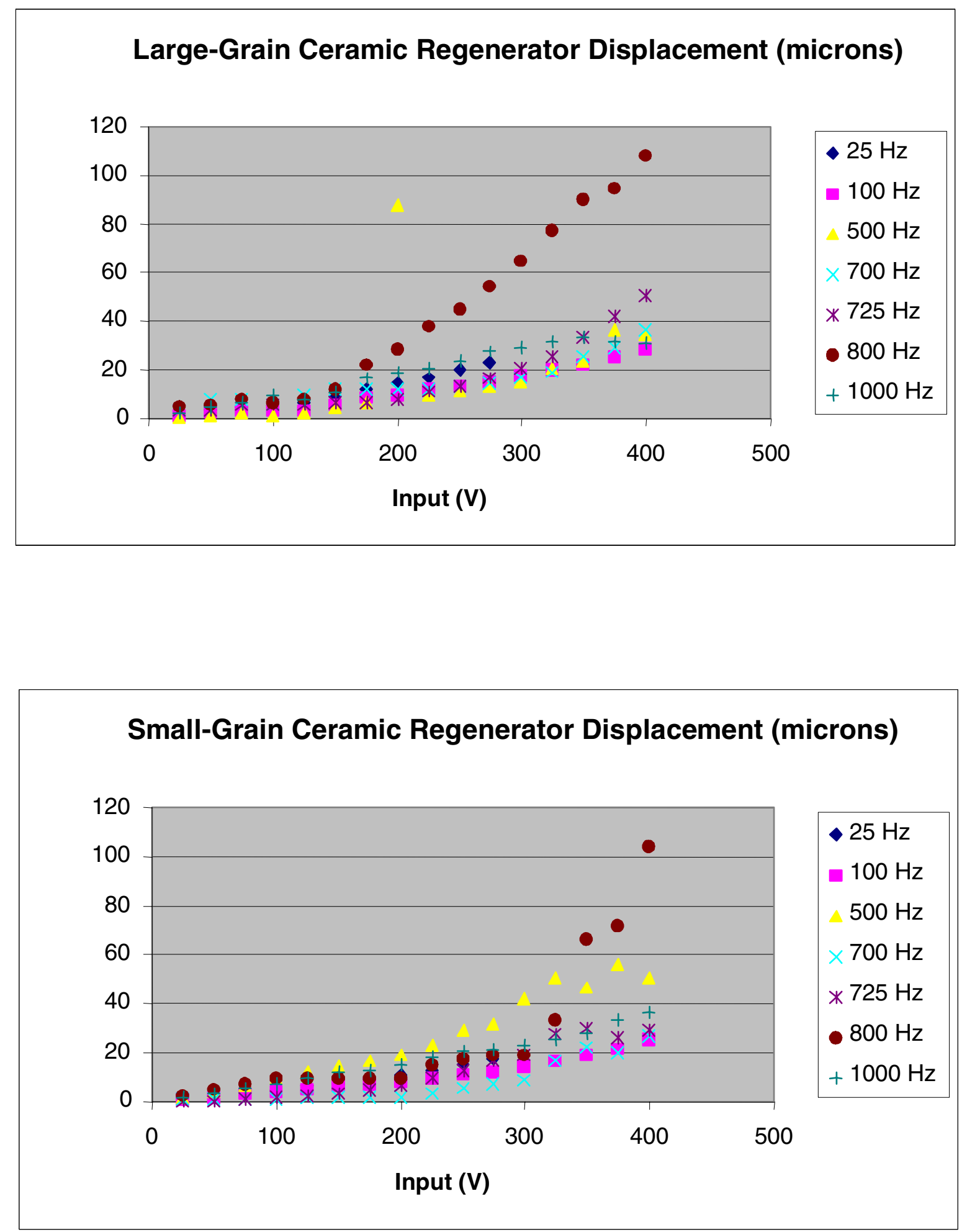

Figure 13. Membrane displacement as a function of voltage at various frequencies for the porous ceramic regenerators. 

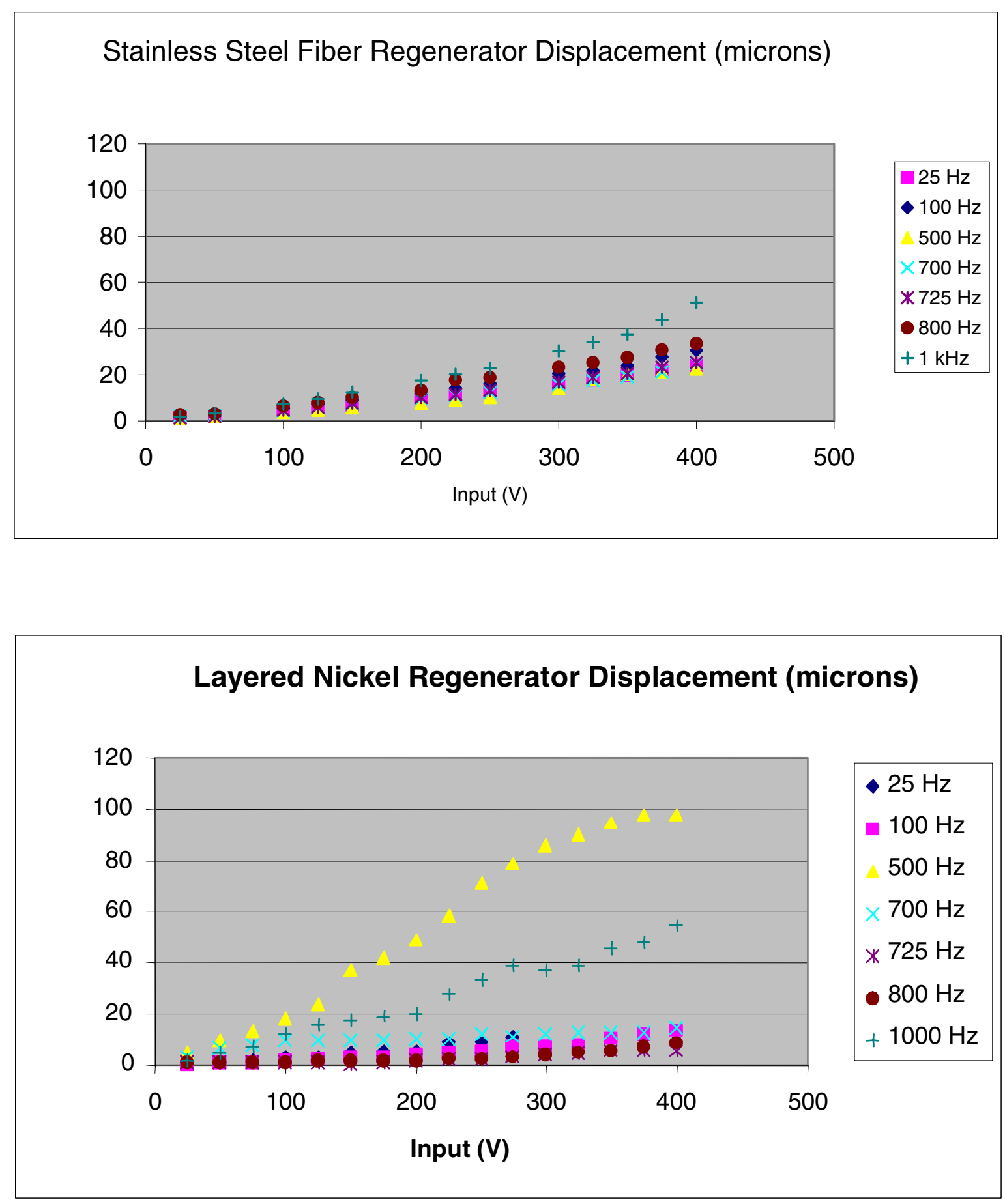

Figure 14.-Membrane displacement as a function of voltage at various frequencies for the stainless steel fiber and layered nickel regenerators. 
Table I.-Summary of membrane displacement for each regenerator at $400 \mathrm{~V}$ input.

\begin{tabular}{|l|c|c|c|}
\hline REGENERATOR & $\begin{array}{l}\text { RESONANT } \\
\text { FREQUENCY }(\mathrm{Hz})\end{array}$ & $\begin{array}{l}\text { DISPLACEMENT @ } \\
\text { RESONANCE (microns) }\end{array}$ & $\begin{array}{l}\text { DISPLACEMENT @ } \\
1000 \text { Hz (microns) }\end{array}$ \\
\hline Layered nickel-photoresist & $500( \pm 100)$ & 98 & 55 \\
\hline Large-grain porous ceramic & $800( \pm 100)$ & 104 & 36 \\
\hline Small-grain porous ceramic & $800( \pm 100)$ & 108 & 31 \\
\hline Random stainless steel fiber & $1500( \pm 100)$ & 50 & 50 \\
\hline
\end{tabular}

\section{B. Stirling Refrigeration Cycle Demonstration}

In order to determine if refrigeration was produced during operation, thermocouple probes were inserted in both the compression and expansion spaces of the test fixture. The piezoelectric actuators were operated at the lower power range of the membrane displacement tests ( $130 \mathrm{~V}$ peak to peak), with a phase lag between actuators of either 45 or 90 degrees to simulate the Stirling cycle. The frequency of operation was varied between 100 to $1000 \mathrm{~Hz}$.

Initial testing produced a temperature difference as high as $8{ }^{\circ} \mathrm{C}$ across the regenerator using the fixture configuration illustrated in Fig. 5. However, it was suspected that heat generated from the piezoelectric actuators was influencing the temperature measurements. After thermally isolating the actuators with the modified fixture shown in Fig. 7, the tests were repeated with the random stainless steel fiber regenerator and both ceramic regenerators. Although the random stainless steel fiber regenerator qualitatively appeared to perform better than the ceramic regenerators in a repeatable fashion, the measurable temperature difference was within the accuracy tolerance of the temperature measurement system.

\section{Discussion of Results}

As expected, the membrane displacement was observed to be directly proportional to input voltage. The effect of input frequency was found to be highly nonlinear around system resonance where the maximum membrane deflection occurred. These results have implications for the prototype design and operation. Specifically, maximum deflection of the membrane translates into maximum swept volume which is directly proportional to overall performance. Therefore, the prototype design will perform optimally at system resonance and the highest input voltage possible.

In addition to swept volume, frequency is another operational parameter directly proportional to Stirling cycle performance. All other parameters being equal, higher frequency operation will result in higher overall performance. At resonance, the membrane displacements for the layered nickel and ceramic regenerators are roughly within $10 \%$ of each other, with the stainless steel fiber regenerator exhibiting about half the deflection of the other regenerators. However, the layered nickel regenerator system resonance is $300 \mathrm{~Hz}$ lower than the ceramic regenerators, and $1000 \mathrm{~Hz}$ lower than the stainless steel fiber regenerator. At $1000 \mathrm{~Hz}$, the layered nickel and stainless steel fiber regenerators exhibit the highest membrane displacement.

The ultimate performance measure is the sustained temperature difference across the regenerator between the compression and expansion spaces (i.e., the Stirling cycle demonstration tests). This temperature difference gives an indirect indication of the thermal characteristics of the regenerator (e.g., transient heat transfer with the working gas and axial conduction losses) as well as the overall performance that is affected by the swept volume and frequency parameters already discussed. Unfortunately, the current results do not yield sufficient evidence to indicate which regenerator candidate provides the best overall performance due to the experimental accuracy of the temperature measurement system. It should be noted that the Stirling cycle demonstration tests run to date were at a significantly lower input power than the maximum power used for the membrane displacement tests $(130 \mathrm{~V}$ vs $400 \mathrm{~V})$. Work is currently underway to increase the input power for the next set of tests with the expectation of increasing the temperature difference across the regenerator.

\section{Concluding Remarks}

A microsystem cooler concept has been developed that incorporates diaphragm actuators to produce the Stirling refrigeration cycle within a planar configuration compatible with below-ambient thermal management of electronics, sensors, optical and radio frequency (RF) systems, microarrays, and other microsystems. The concept has evolved 
into a design incorporating DRIE fabricated electrostatically-driven comb drive diaphragms with a spiral spring mounting for maximum deflection. Fabrication of a prototype device based on this design is currently underway.

The regenerator part of the microsystem cooler is critical to the feasibility and performance of the device. A test fixture was constructed to characterize this critical component, and several regenerator candidates were fabricated and tested. Test results indicate that each regenerator exhibits a unique system resonant frequency where the greatest membrane deflection occurs, and hence the greatest swept volume. Assembly of the prototype device will make use of this data to select the regenerator with the best combination of high resonant frequency and maximum membrane deflection.

Demonstration of the Stirling refrigeration cycle within the test fixture was not definitively achieved during this initial set of test runs as measured by a significant temperature difference across the regenerator. Future tests are planned to increase the input voltage for greater membrane deflection.

\section{References}

${ }^{1}$ Moran, M.E. "Micro-Scale Avionics Thermal Management," 34th International Symposium on Microelectronics (IMAPS), Oct 9-11, 2001 (NASA TM-2001-211095, Aug, 2001).

${ }^{2}$ Stetson, N.B., "Miniature Integral Stirling Cryocooler", U.S. Patent No. 5,056,317, October 15, 1991.

${ }^{3}$ Solomon, R., "Integrated Refrigerated Computer Module," U.S. Patent No. 5,349,823 (Assignee: Intel Corp.), September 27, 1994.

${ }^{4}$ Bowman, L., et al., "Microminiature Stirling Cycle Cryocoolers and Engines," U.S. Patent No. 5,457,956 (10/17/95) and continued-in-part in 5,749,226 (5/12/98) and 5,941,079 (8/24/99) (Assignee: Ohio Univ.).

5 Moran, M.E., "Micro-Scalable Thermal Control Device," US Patent No. 6,385,973 B1, May 14, 2002.

${ }^{6}$ Moran, M.E., "Multidisciplinary Analysis of a Microsystem Device for Thermal Control," Proceedings of the 11th Thermal \& Fluids Analysis Workshop, Cleveland, OH, August 21-25, 2000. 
Public reporting burden for this collection of information is estimated to average 1 hour per response, including the time for reviewing instructions, searching existing data sources, gathering and maintaining the data needed, and completing and reviewing the collection of information. Send comments regarding this burden estimate or any other aspect of this collection of information, including suggestions for reducing this burden, to Washington Headquarters Services, Directorate for Information Operations and Reports, 1215 Jefferson Davis Highway, Suite 1204, Arlington, VA 22202-4302, and to the Office of Management and Budget, Paperwork Reduction Project (0704-0188), Washington, DC 20503.

\begin{tabular}{|l|l|l|}
\hline 1. AGENCY USE ONLY (Leave blank) & $\begin{array}{c}\text { 2. REPORT DATE } \\
\text { September } 2004\end{array}$ & $\begin{array}{r}\text { 3. REPORT TYPE AND DATES COVERED } \\
\text { Technical Memorandum }\end{array}$ \\
\hline
\end{tabular}

\section{TITLE AND SUBTITLE}

Microsystem Cooler Development

\section{FUNDING NUMBERS}

Matthew E. Moran, Danielle M. Wesolek, Bruk T. Berhane, and Keith J. Rebello

7. PERFORMING ORGANIZATION NAME(S) AND ADDRESS(ES)

National Aeronautics and Space Administration

John H. Glenn Research Center at Lewis Field

Cleveland, Ohio 44135-3191

WBS-22-319-20-X1

8. PERFORMING ORGANIZATION

REPORT NUMBER

E-14766

9. SPONSORING/MONITORING AGENCY NAME(S) AND ADDRESS(ES)

National Aeronautics and Space Administration

Washington, DC 20546-0001

10. SPONSORING/MONITORING

AGENCY REPORT NUMBER

NASA TM-2004-213307

AIAA-2004-5611

\section{SUPPLEMENTARY NOTES}

Prepared for the Second International Energy Conversion Engineering Conference sponsored by the American

Institute of Aeronautics and Astronautics, Providence, Rhode Island, August 16-19, 2004. Matthew E. Moran,

NASA Glenn Research Center; and Danielle M. Wesolek, Bruk T. Berhane, and Keith J. Rebello, Johns Hopkins

University, Applied Physics Laboratory, Laurel, Maryland 20723. Responsible person, Matthew E. Moran,

organization code 5480, 216-433-8324.

12a. DISTRIBUTION/AVAILABILITY STATEMENT

12b. DISTRIBUTION CODE

Unclassified - Unlimited

Subject Category: 31

Distribution: Nonstandard

Available electronically at http://gltrs.grc.nasa.gov

This publication is available from the NASA Center for AeroSpace Information, 301-621-0390.

13. ABSTRACT (Maximum 200 words)

A patented microsystem Stirling cooler is under development with potential application to electronics, sensors, optical and radio frequency (RF) systems, microarrays, and other microsystems. The microsystem Stirling cooler is most suited to volume-limited applications that require cooling below the ambient or sink temperature. Primary components of the planar device include: two diaphragm actuators that replace the pistons found in traditional-scale Stirling machines; and a micro-regenerator that stores and releases thermal energy to the working gas during the Stirling cycle. The use of diaphragms eliminates frictional losses and bypass leakage concerns associated with pistons, while permitting reversal of the hot and cold sides of the device during operation to allow precise temperature control. Three candidate microregenerators were custom fabricated for initial evaluation: two constructed of porous ceramic, and one made of multiple layers of nickel and photoresist in an offset grating pattern. An additional regenerator was prepared with a random stainless steel fiber matrix commonly used in existing Stirling machines for comparison to the custom fabricated regenerators. The candidate regenerators were tested in a piezoelectric-actuated test apparatus designed to simulate the Stirling refrigeration cycle. In parallel with the regenerator testing, electrostatically-driven comb-drive diaphragm actuators for the prototype device have been designed for deep reactive ion etching (DRIE) fabrication.

14. SUBJECT TERMS

Coolers; Stirling cycle; Thermoacoustic refrigerators; Refrigerators;

Microelectromechanical systems

\begin{tabular}{|c|c|}
\hline $\begin{array}{c}\text { 17. SECURITY CLASSIFICATION } \\
\text { OF REPORT } \\
\text { Unclassified }\end{array}$ & $\begin{array}{c}\text { 18. SECURITY CLASSIFICATION } \\
\text { OF THIS PAGE } \\
\text { Unclassified }\end{array}$ \\
\hline
\end{tabular}

NSN 7540-01-280-5500

19. SECURITY CLASSIFICATION OF ABSTRACT

Unclassified
15. NUMBER OF PAGES

16

16. PRICE CODE

20. LIMITATION OF ABSTRACT

Standard Form 298 (Rev. 2-89)

Prescribed by ANSI Std. Z39-18 298-102 

